논문 2019-2-7 http://dx.doi.org/10.29056/jsav.2019.12.07

$$
\begin{gathered}
\text { 소프트웨어 목적물의 전달체계 분석과 신뢰성 검증 } \\
\text { 김도현*, 이규대**† }
\end{gathered}
$$

\title{
Management of Reliability and Delivery for Software Object Material
}

\author{
Do-Hyeun Kim*, Kyu-Tae Lee***
}

요 약

\begin{abstract}
소프트웨어의 저작권 도용이 증가하면서 유사성을 판단을 요구하고 있지만, 분석을 위한 목적물의 확보 및 이동에 대한 신뢰성 확보가 중요시 되고 있다. 감정을 위한 데이터로 사용되는 목적물 자료는 법원 및 경찰 서와 같은 분쟁 처리 기관에서 감정인에게 제공되는 핵심적인 데이터이다. 목적물은 분쟁 당사자가 저작권 위원회에 제출하고 최종적으로 감정 전문가에게 원본상태로 전달되는 이동 과정을 갖는다. 그러나 분쟁 당사 자가 감정 결과에 만족하지 않으면 목적물의 신뢰성에 대한 이의를 제기한다. 특히, 소프트웨어 목적물은 파 일 형식으로 제작되어, 변형이나 수정이 가능한 것으로 인식되고 있다. 따라서 목적물에 객관성을 부여하는 방법이 다양한 방식으로 검토되고 있으며, 포렌식이 하나의 방법으로 제안되고 있다. 본 연구는 실제 사례의 감정 프로세스를 통해 목적물의 이동 및 신뢰성을 확보하는 방법을 연구하였다.
\end{abstract}

\begin{abstract}
On increasing illegal software copyright, the need for similarity analysis is now rising. The reliability of object material are becoming important when it's moving from developer to evaluation experts. Object material as a comparison data, is the important data to the evaluation expert which is delivered from agencies such as courts and police stations. The object material is submitted at first to the Copyright Commission and then delivered to the evaluation expert with safe. However, if the similarity result is not satisfied to the both side, they will claim to the reliability of the object material such as source code modification or revision etc. Software objects is produced in a file format and are recognized as being able to be modified. Therefore, the reliability to the object material is studied in various ways, and a forensic is proposed as one method. This study showed the suggestion to keep reliability of the object material through the actual evaluation cases.
\end{abstract}

한글키워드 : 신뢰성, 저작물, 포렌식, 불법복제, 유사성

keywords : reliability, object material, forensic, illegal copy, similarity

* 국립 제주대학교 컴퓨터공학과 교수

\section{1. 서 론}

** 국립공주대학교 정보통신공학부 교수

† 교신저자: 이규대(email: ktlee@kongju.ac.kr)

접수일자: 2019.11.30. 심사완료: 2019.12.17.

게재확정: 2019.12.20.

소프트웨어감정의 자료로 사용되는 목적물은 법원이나, 경찰청 등 분쟁처리 기관에서 감정인 
에게 제공되는 기본 자료를 말한다. 감정목적물 은 분쟁기관에서 저작권위원회에 전달되고, 감정 인에게 제공된다[1]. 목적물은 분쟁당사자가 적극 적으로 제출하는 경우와 복제의심의 대상자가 자 료제출을 거부함에 따라 압수 및 수색으로 취득 되는 감정 자료를 의미한다. 최초 입수된 목적물 은 회손 및 변형의 의혹을 방지하기 위한 장치가 있을 경우 원본에 대한 보존이 가능하지만, 목적 물의 변형이 의심되는 경우에는 감정결과에 대한 의혹이 제기될 가능성이 내재되어 있다. 특히 분 쟁당사자가 감정결과에 만족하지 못한 경우, 목 적물의 신뢰성에 문제를 제기하게 되고, 목적물 의 객관성을 입증하지 못할 경우, 감정의 결과 판단에 영향을 미치게 된다. 특히 소프트웨어 감 정목적물은 파일 형식으로 제작되어, 쉽게 변형 이나, 훼손이 가능한 것으로 인식되고 있다. 때문 에 목적물의 객관성을 부여하기 위한 방안이 다 각도로 고민되고 있으며, 포렌식처리 방법이 하 나의 방법으로 제시되고 있다[2]. 본 연구에서는 실제적인 감정프로세스를 통해 신뢰성이 확보될 수 있는 방안에 대해 다루었다.

\section{2. 감정목적물의 특징}

\section{1 정보기기의 목적물}

정보단말기로 사용되는 대부분의 정보기기는 프로세서를 기반으로 하는 입출력 인터페이의 구 조의 하드웨어와 운영체제를 기반으로 하는 디바 이스 소프트웨어와 응용소프트웨어의 일체형으 로 제작되고 있다. 분쟁이 발생되는 경우의 감정 목적물은 하드웨어, 소프트웨어 또는 이들이 결 합된 시스템 형태의 자료가 목적물로 정의된다. 목적물로서의 장치 구성은 크게 그림 1 과 같이 하드웨어와 소프트웨어로 구분될 수 있으며, 하
드웨어는 마이크로프로세서를 중심으로 하는 주 변장치와 입출력장치를 연결하는 회로를 설계하 고, 회로기판 $(\mathrm{PCB})$ 에 부품을 장착하여 제작된다. 하드웨어는 박스형태의 실제적 형상으로 설계되 며, 크기, 색상, 무게, 소비전력, 커넥터 등이 설계 자의 독창성으로 구현된다. 박스형태의 하드웨어 내부에 실장되는 프로그램 소프트웨어는 각 장치 간의 연결신호 및 입출력 신호를 제어하도록 작 성되고, 특정 기능이 디바이스 드라이버로 연결 되도록 하고, 운영체제를 기반으로 하는 임베디 드 소프트웨어와 응용프로그램으로 설계된다. 따 라서 소프트웨어 목적물은 그림 1과 같이 운영체 제를 구성하는 소스코드, 사용자 응용프로그램은 구성하는 소스코드로 구성된다.

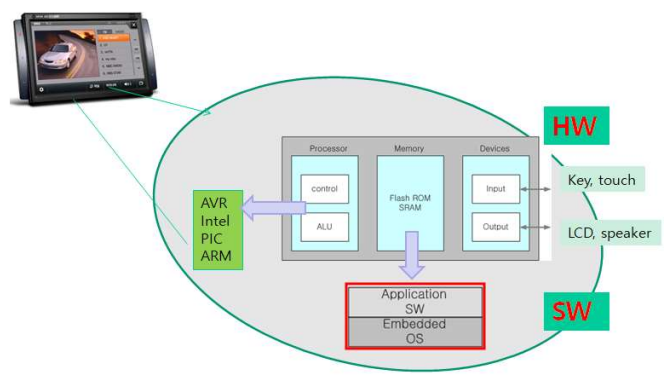

그림 1. 정보기기 목적물의 구성

Fig. 1. Embedded system material

\section{2 소프트웨어 목적물}

소프트웨어는 시스템에 적용된 프로세서에 따 라 사용된 언어나 운영체제에 차이가 존재한다. 임베디드 시스템과 같이 운영체제를 기반으로 작 성되는 상황에서는 커널의 구조, 모델, 디바이스 드라이버, 사용자 응용프로그램 등이 소프트웨어 로서 목적물 대상이 된다. 또한 사용된 언어의 종류 및 동작의 흐름도는 소프트웨어의 구조와 기능을 결정하는 요소로 활용된다[3].

소프트웨어 소스코드 제작 과정은 그림 2와 같 
이 플로우 차트 순서도를 작성하면서 시작된다. 작업의 시작점을 기준으로, 초기화, 데이터입력, 데이터 처리, 데이터 저장, 상태점검에 따른 분기 등의 순서에 따라 작성되고, 업무가 종료되면 소 프트웨어 흐름도 종료된다. 순서도 작성이 완료 되면, 소스코드 코딩작업을 하기 위한 언어를 선 택하고, 컴파일이 가능한 작업환경으로 소스코드 작업을 진행한다. 작성된 소스코드는 텍스트 형 태의 판독이 가능한 문서이며, 시스템에 삽입 (download) 되어 실행이 되기 위해서는 기계어 번역을 위한 컴파일(compiler) 작업을 수행한다. 이 작업으로 기계어 상태의 이진코드(hex code) 가 만들어 진다[4][5][6]. 이러한 일련의 작업 중 에서 소프트웨어 소스코드는 플로우 차드를 보고 작성된 문서형태의 코드를 의미하며, 육안으로 판독이 가능하기 때문에 감정목적물의 핵심 자료 이고, 기본 자료로 지정된다. 그러나 이 소스코드 에 작업자의 고유한 개발정보인 저작권이 포함되 기 때문에 보호가 되어야하는 목적물이고, 이동 간에 훼손되거나 변형을 방지해야 한다.

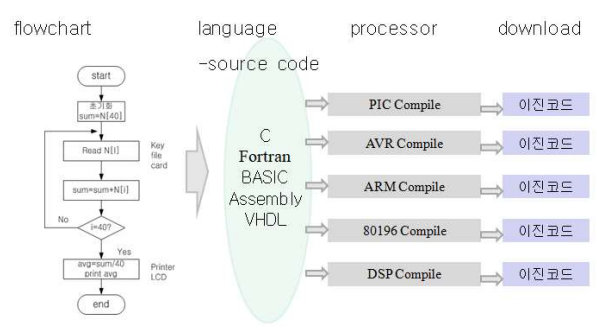

그림 2. 프로그램 작성 흐름도

Fig. 2. Program Flowchart

특히 소프트웨어 목적물은 파일형태로 작성되 고, 메모리스틱이나, $\mathrm{CD}$ 에 저장되어 이동되고, 언제든 읽고 쓰기가 가능한 형태로 작성되기 때 문에 목적물로 취급 시에 변형을 방지하거나, 변 형 시 흔적이 남을 수 있는 장치가 부가되어야 하는 필요성이 있다.

\section{3. 감정목적물의 이동}

감정목적물은 그림 3 과 같이 법원이나 경찰청 으로 확보된 자료를 저작권위원회에 전달하고, 저작권위원회에서는 감정인을 지정한 후, 감정인 에게 목적물로써 제공한다. 감정인은 이 자료를 기준으로 유사성과 도용의 가능성을 분석하고, 결과가 도출되면, 분석 결과와 함께 사용한 목적 물을 위원회에 반납한다. 저작권위원회는 감정인 으로부터 반납 받은 목적물을 감정서와 함께 의 뢰기관으로 보내면 감정이 종료되고, 감정 목적 물의 이동이 완료된다.

분쟁의뢰인이 목적물을 직접 제출하거나, 경찰 의 압수 또는 수색에 의해 최초 확보된 감정목적 물은 법원에서 위원회로 이동시, 그리고 위원회 에서 감정인에게 이동시, 변형과 훼손에 대한 엄 격한 보안방법이 요구되고 있다. 현재의 방법에 대한 문서화나 개선된 이동방법에 대한 정립이 필요한 시점이다. 이는 분쟁당사자의 목적물에 대한 의혹 제기 시, 객관적인 이동체계에 대한 자료로 활용되어 불안감을 최소화하는 방안으로 활용이 되는 장점이 있다. 특히 법원에서 위원회 로의 이동과, 위원회에서 감정인에게 이동시점에 서의 객관성 확보에 대한 절차 및 방법이 요구된 다.

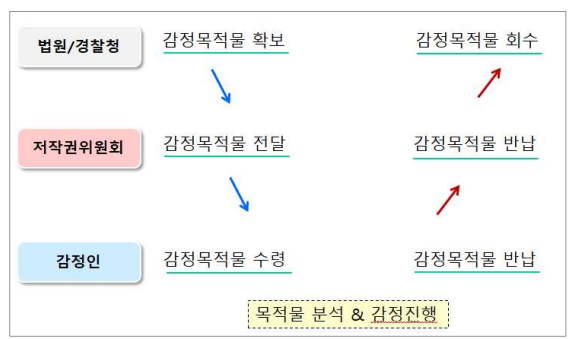

그림 3. 감정목적물의 이동

Fig. 3. Movement of Object material 


\section{4. 목적물의 신뢰성}

감정목적물은 감정진행단계에서 이동될 때 마 다, 무결성과 안전성이 보장되어야 분쟁의 소지 를 최소화 할 수 있다. 또한 감정 결과가 감정인 에 따라 크게 차이가 나지 않도록 감정 과정과 각 단계별 감정 방법을 상세히 기술하고, 다음과 같이 정성적인 판단에 대해서도 명확하게 기술되 어야 한다.

- 감정 도구를 지정하고, 사용법과 실행 환경/옵 션 등을 명시.

- 가능하다면 감정 도구를 두 가지 이상 사용하여 도구의 신뢰성을 보장. 예를 들어 목적물 규모 산정을 위한 도구와 유사도 비교를 위한 도구를 서로 다른 도구를 사용하고, 두 도구의 라인 분 석 결과가 동일성.

- 오픈 소스나 창작성이 없는 소스를 제거할 경 우, 제거한 이유와 위치를 명시.

- 유사도 비교 도구의 결과를 육안으로 확인하여 유사 부분에 대한 정성적 판단을 수행하고, 그 판단의 이유와 위치를 최대한 기록

- 완성도 감정의 경우 미완성 부분에 대해 입력 데이터와 테스트 방법을 명시.

감정목적물로 소프트웨어 소스코드가 완전하 게 제공되지 않는 경우에는 실행파일을 대상으로 분석을 해야 하는데, 이 경우는 hexa 코드에서 유의미한 문자를 탐색하는 방법으로 도용의 근거 를 추적한다. 따라서 정확한 감정이 수행되기 위 해서는 양측의 프로그램 소스코드가 확보되어야 하며, 동시에 양측의 의심을 해소하기 위한 목적 물의 신뢰성 확보 방법으로 적용하여야 한다.

\section{1 디지털포렌식 절차}

디지털 포렌식은 컴퓨터를 매개로 이루어지는 범죄에 대한 법적 증거자료 확보를 위해 컴퓨터 저장매체와 네트워크로 부터 자료를 수집, 분석 및 보존하여 법적 증거물로써 제출할 수 있도록 하는 일련의 절차와 행위를 정의하고 있다[2]. 사 용방법에 따라 다음과 같이 분류하며, 디스크 포 렌식, 시스템포렌식, 네트워크포렌식, 인터넷포렌 식, 모바일포렌식, 데이터베이스포렌식, 암호포렌 식, 회계포렌식 등이 있다.

주로 증거 확보 및 침해의 흔적을 탐색하는 방 법으로 적용되는 것으로 다음과 같이 사고대응, 정보추출 포렌식으로 구분하여 사용된다.

사고대응 포렌식은 해킹 등 침해 시스템의 로 그, 백도어, 루트킷 등을 조사하여 침입자의 신 원, 피해내용, 침입경로 등을 파악하는 것으로 네 트워크 기술과 서버의 로그분석기술, 유닉스, 리 눅스, 윈도우 서버 등 운영체제에 대한 기술적 능력이 요구된다.

정보 추출 포렌식은 범행 입증에 필요한 증거 를 얻기 위하여 디지털 저장매체에 기록되어있는 데이터를 복구하거나 검색하는 것으로, 회계시스 템에서 필요한 계정을 찾아 범행을 입증할 수 있 는 수치 데이터를 분석하거나 E-mail등의 데이 터를 복구 및 검색하여 증거를 찾아내는 기술로 사용된다.

포렌식 분석은 그림 4 와 같이 5 단계로 구분되 며, 사전준비, 증거물 수집, 이송 및 보관, 증거분 석, 보고서 작성 순서로 진행된다.

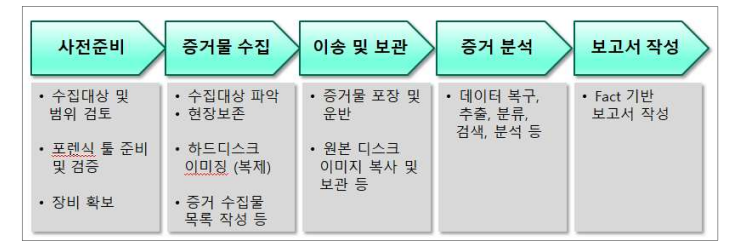

그림 4. 디지털 포렌식 분석 5단계

Fig. 4. Analysis Steps of digital forensic 


\section{2 감정목적물 분석사례}

\subsection{1 소스코드 목적물}

건강스포츠 운동기구인 런닝머신을 구성하는 시스템 및 구동 프로그램을 목적물로 제공된 감 정사례로서, 고소인의 프로그램을 피고소인이 무 단 도용하여 유사제품을 제작한 것으로 의심되어 제기된 사건이다. 피고소인의 프로그램이 고소인 의 고유기능 프로그램을 도용한 것인지에 대한 판단을 위한 사례이다. 감정대상 제품의 특징은 모터에 의해 구동되는 런닝벨트 장치에 마이크로 프로세서를 응용한 제어회로를 연결하여, 모터 및 센서 입력, 디스플레이 정보 등을 제어하는 프로그램으로 구성되었다. 장치는 프로세서의 순 차적 제어에 의해 런닝머신 모터가 구동되고, 운 동자의 운동량을 센싱하여 개인의 운동 정보를 저장 및 전송하는 기능을 갖는다. 소스코드가 제 공된 경우는 그림 5 와 같이 소스코드 비교도구 beyond compare 를 사용하여, 라인단위 비교에 의한 유사성 도출이 가능하다. 그림은 양측의 소 스코드가 제공되었을 때 양측의 코드라인을 좌우 로 배치하고, 유사성이 있거나, 일치되는 라인의 위치를 표시하는 방법으로 작업자에게 육안 검색 이 가능하게 한다.

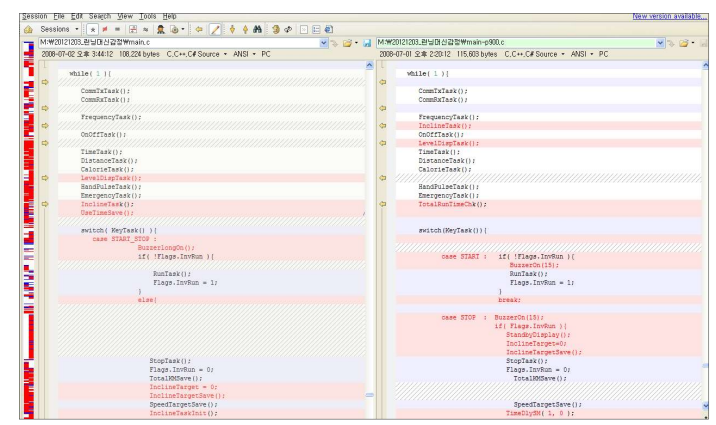

그림 5. beyond compare 도구의 비교 예

Fig. 5. Beyond Compare tool GUI

위의 감정사례의 경우 감정항목으로 분류된 9
개 항목에 대응되는 프로그램 소스코드의 라인단 위 비교를 수행한 분석 결과를 얻는다. 표 1 은 감정항목별 분석결과를 도출한 것으로 유사성 $51.51 \%$ 의 비교결과로 유사성이 있는 것으로 판 단된 결과를 보인다. 소스코드목적물은 라인단위 분석이 가능한 목적물로 분석이 용이하나, 목적 물 이동간의 변형우려가 있어 이에 대한 방지절 차가 요구되는 부분이다.

표 1. 소스코드 항목 비교결과

Table 1. Result of source code compare

\begin{tabular}{|c|c|c|}
\hline & 항목 & $\begin{array}{c}\text { 유사도 } \\
(\%)\end{array}$ \\
\hline 1 & 선언부 & 48.0 \\
\hline 2 & 변수선언부 & 43.5 \\
\hline 3 & 통신인터럽트 & 100 \\
\hline 4 & 타이머인터럽트 & 42.3 \\
\hline 5 & 디스플레이함수 & 21.6 \\
\hline 6 & 시간,거리,칼로리 함수 & 87.7 \\
\hline 7 & 심박수,운동시작,정지,비상정지 & 40.0 \\
\hline 8 & main 초기화,시작,정지 & 35.0 \\
\hline \multirow[t]{2}{*}{9} & main 증가,감소 설정 함수 & 45.5 \\
\hline & 평 균 & $51.51 \%$ \\
\hline
\end{tabular}

\subsection{2 실행코드 목적물}

감정대상은 linux 운영체제를 기반으로 공개 프로그램을 사용하고 공개소스로서 다양한 기기 에 설치되어 방송수신기의 기능이 구현되는 장치 이다. 제작자는 독자적인 하드웨어를 제작하고, 하드웨어에 사용된 수신기능에 적합한 디바이스 드라이버를 개발하여 적용함으로써 새로운 형태 의 방송수신 장치를 구성한다. 이때 동작메뉴는 공개프로그램을 사용하고 있으므로, 화면에서의 사용자 인터페이스는 공개프로그램에 표준화된 모습을 보이게 된다. 장치의 실행파일은 홈페이 지와 수신 장치의 모델에 적합한 이미지파일을 다운로드할 수 있다[7][8]. 
실행코드 목적물의 파일구조는 이진코드 (binary code)로 저장된다. 이것은 프로그램 소스 코드가 컴파일 되어 완성된 실행코드로서 프로그 램으로서의 판독에 제한이 있다. 그러나 프로그 램 내에 문자가 포함된 경우, 이진코드를 판독하 는 프로그램을 사용하여, 문자분석(텍스트)으로 도용을 추정할 수 있는 분석이 가능하다. 바이너 리 파일의 분석은 hexa code 형태로 판독하고, 해당되는 ASCII code로 표현하여 문자정보를 비 교하는 방법이다. 감정에서는 hexa 파일을 편집 하는 여러 가지 도구 중에서 그림 6과 같은 Funduc Software사의 FS Hex Editor가 사용된 다. 이 프로그램은 바이너리 형태의 파일을 분석 하고, 수정이 가능한 기능이 있다[9].

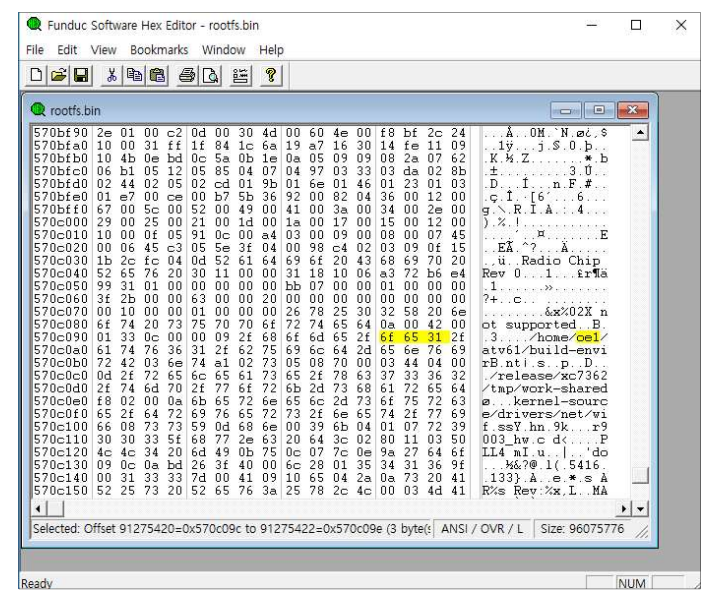

그림 6. FSHED의 실행화면

Fig. 6. Compare display of FSHED tool

이 방법으로 분석한 화면은 그림 7과 같으며, 특정 코드의 판독으로 저작권의 도용 유무를 판 단하는 방법이 사용된다.

실행코드 목적물은 이동시 소스코드 목적물에 비해 변형의 우려는 적으나, 일대일 비교가 불가 능하여, 위의 분석과 같이 간접방법으로 유사성 분석을 하는 어려움이 있다.

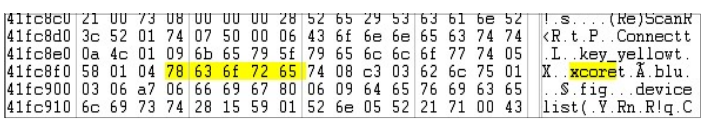

그림 7. 실행코드 분석 화면

Fig. 7. Hexa code analysis window

이상과 같이 소스코드 목적물은 파일로 제공 되어, 유사성 판독이 가능한 감정목적물로 활용 되지만, 이동과정에서의 변형을 보장하기 위한 방법이 부가되어야 하며, 실행코드만으로 제공되 는 경우는 유사성 판단에 부족한 정보를 제공하 지만, 변형이나 훼손의 가능성이 적은 장단점을 보인다.

\section{5. 결 론}

소프트웨어감정은 프로그램 소스코드가 파일 형식으로 제공되기 때문에 변형이나, 삭제의 가 능성을 포함하고 있다. 때문에 분쟁 당사자 들은 감정 유사도의 결과가 만족되지 않을 경우, 감정 인이 사용한 목적물의 신뢰성에 의혹을 제기하게 된다. 본 연구에서는 목적물이 확보되는 단계부 터, 감정인에게 제공되는 단계의 이동과정에서 목적물의 훼손과 변형을 방지 할 수 있는 방안에 대해 연구하였다. 포렌식의 목적물 취급 단계를 규정하고, 문서화하는 방법으로 분쟁의 소지를 최소화 할 수 있는 감정절차에 적용 가능할 것으 로 판단된다.

\section{참 고 문 헌}

[1] Raj Kamal, "Embedded systems Architecture Programming and Design", 2nd ed. MacGraw Hill Companies; 2015. p.5.(Book) [ISBN 0-07-049470-3 ] 
[2] 정익래, 홍도원, 정교일, "디지털포렌식 기술 및 동향”, 전자통신동향분석, 제 22 권, 2007.2

[3] $\mathrm{Kyu}^{-T a e}$ Lee, Hyun-Chang Lee, Jang-Geun Ki. "Establishment of the Subtitle on Materials for Evaluating Intellectual Ownership", International Journal of Signal Processing, Image Processing and Pattern Recognition. pp.79-88, Sep., 2017. http//dx.doi.org/ 10.14257/ijsip.2017.10.9.09

[4] M. M. Swift, B. N. Bershad, and H. M. Levy. "Improving the Reliability of Commodity Operating Systems", ACM Trans. on Computer Systems. pp.77-110, Sep., 2003. DOI: 10.1.1.107.2596

[5] M. M. Swift, M. Annamalai, B. N. Bershad, and H. M. Levy. "Recovering Device Drivers", ACM Trans. on Computer Systems. pp.333-360., Nov. 2006. http://u.cs.biu.ac.il/ wiseman/2os/bugs/swift 1.pdf

[6] M. Rajagopalan, M. A. Hiltunen, T. Jim, and R. D. Schlichting. "System Call Monitoring Using Authenticated System Calls", IEEE Trans. on Dependable and Secure Computing. pp.216-229, July 2006. DOI: $10.1109 /$ TDSC.2006.41

[7] T. Naughton, W. Bland, G. Vallee, C. Engelmann, and S. L. Scott. "Fault Injection Framework for system Resilience Evaluation", Proc. of the Resilience"09. pp.23-28, June 2009. https://www.christian -engelmann.info/publications/naughton09fau lt.pdf

[8] Compare files and folders [Internet], 2018 [updated 2018 Oct 10; cited 2018 Oct 10]. Available from: http://www.scooter software.com/features.php?zz=features_focu sed (website)

[9] V.J. Mooney, D.M. Blough. "A hardware-software real-time operating system framework for SoCs", IEEE Design \& Test of Computers. pp.44-51, Nov. 2002. DOI: 10.1109/MDT.2002.1047743

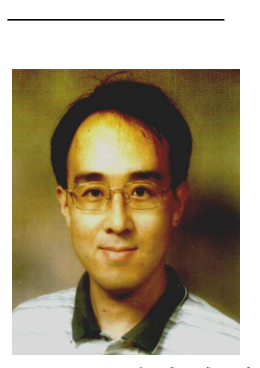

저 자 소 개

김도현(Do-Hyeun Kim)

2000.8 경북대 전자공학과(정보통신전공) 박사 2004.9 현재 국립 제주대학교 공과대학

컴퓨터공학전공 교수

<주관심분야> 사물인터넷, 예측 및 최적 제어, 모바일 컴퓨팅, 임베디드 소프트웨어

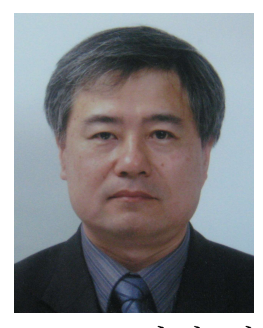

이규대(Kyu-Tae Lee)

1991 고려대 전자공학과 박사

1992 현재 공주대학교 정보통신공학부 교수 <주관심분야> 신호처리, $\mathrm{VLC}$, 저작권보호 